\title{
Very Late Relapse of Testicular Tumour in Combination with Renal Cancer and Their Retroperitoneoscopic Removal
}

\author{
Mihály Murányi, Morshed Ali Salah, Béla Tállai, Mátyás Benyó, and Tibor Flaskó \\ Department of Urology, University of Debrecen Medical School and Health Science Center, Nagyerdei krt. 98, \\ Debrecen 4032, Hungary \\ Correspondence should be addressed to Mihály Murányi, vezermurmillo@gmail.com
}

Received 22 May 2011; Revised 27 July 2011; Accepted 5 August 2011

Academic Editor: Jahn M. Nesland

Copyright (๑) 2011 Mihály Murányi et al. This is an open access article distributed under the Creative Commons Attribution License, which permits unrestricted use, distribution, and reproduction in any medium, provided the original work is properly cited.

\begin{abstract}
Late relapse of a testicular cancer is an uncommon occurrence. We report a case of late relapse of a testicular tumour combined with a renal cancer and their successful removal with retroperitoneoscopy. The 36-year-old patient underwent left orchiectomy, retroperitoneal lymph node dissection, and chemotherapy, because of mixed tumor including teratoma and embryonal carcinoma. 18 years after the successful primary therapy elevated serum alpha-fetoprotein level had been confirmed, then MRI and PET-CT scans demonstrated a $30 \mathrm{~mm}$ left renal mass and $22 \mathrm{~mm}$ retroperitoneal lymph node above the bifurcation of the left common iliac artery. We performed retroperitoneoscopic lymph node dissection and left renal tumour resection in the same session. The histology revealed embryonal carcinoma for the retroperitoneal lymph node and renal cell carcinoma for the left renal mass. We can conclude that late followup of patients with testicular tumour is important. Retroperitoneoscopy is feasible approach for the removal of retroperitoneal lymph node metastasis and resection of renal tumor.
\end{abstract}

\section{Introduction}

Most recurrences of testicular cancer after curative therapy occur in the first 2 years [1]. Recurrences are uncommon after 2 years. Late relapse is defined as tumour recurrence more than 2 years after complete remission following primary treatment. Many years after successful treatment, second primary malignancies can occur [2-4].

Herein we report a case of late relapse of a nonseminomatous germ cell tumour 18 years after first complete remission, combined with a renal cancer and their successful treatment with retroperitoneoscopy.

\section{Case Report}

The 36-year-old patient had a history of left radical inguinal orchiectomy, open extended bilateral retroperitoneal lymph node dissection, and chemotherapy because of testicular cancer before 18 years in another center. The histology revealed a mixed tumor including teratoma and embryonal carcinoma in the left testicle and in the paraaortic lymph nodes. The treatment was successful. During 12 year followup period, there was no recurrence.

18 years after the primary therapy, elevated serum alpha-fetoprotein level $(50,24 \mathrm{ng} / \mathrm{mL})$ was confirmed. By physical examination, there was no abnormality. MRI scan demonstrated a $30 \mathrm{~mm}$ left renal mass (Figure 1) and $22 \mathrm{~mm}$ retroperitoneal lymph node above the bifurcation of the left common iliac artery (Figure 2). PET-CT scan confirmed this finding and showed intensive fluorodeoxyglucose uptake in both lesions. At that time, he was referred to our center. We performed retroperitoneoscopic lymph node dissection and left renal tumor resection at the same session. The operation time was 285 minutes, and blood loss was $150 \mathrm{~mL}$. Complication did not occur. Transfusion or conversion to open surgery was not necessary. The postoperative period was uneventful, analgesic requirements were moderate, and hospital stay was 3 days. The histology revealed embryonal carcinoma for the retroperitoneal lymph node and renal cell carcinoma for the left renal mass. The renal cell carcinoma was independent of the germ cell tumour. Immunohistochemical staining showed that tumour cells from the retroperitoneal lymph 


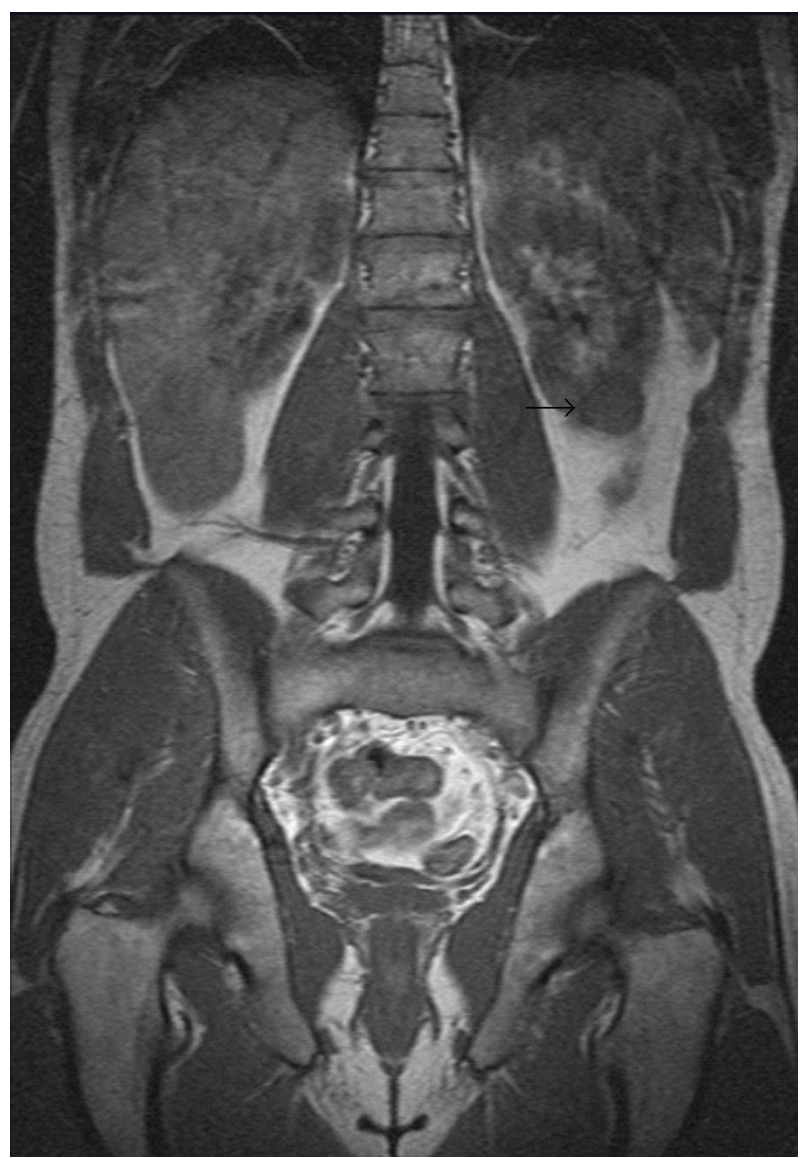

FIGURE 1: Coronal magnetic resonance imaging scan demonstrating $30 \mathrm{~mm}$ left renal mass (arrow).

node were negative for vimentin, CD10, and CD30, in contrast with tumour cells from the renal mass, which were positive for vimentin and CD10 and negative for CD30. Six months after the operation, the patient had no recurrence and serum alpha-fetoprotein level was normal.

\section{Discussion}

Late relapses of nonseminomatous germ cell tumours are rare $1-6 \%$ of patients have a late relapse [5-8]. Late relapse may occur at any time, even 32 years after primary treatment $[6,9]$.

The most frequent location of late relapse is retroperitoneal space. The lungs and the mediastinal lymph nodes are rarely affected $[1,6,8,10]$. After retroperitoneal lymphadenectomy, relapse in the retroperitoneum is rare, the most likely site of recurrence being the chest [11].

The optimum treatment for the patient depends on the primary treatment, histological type of the tumour, and the location of late relapse. The surgical approach seems to be the best choice. Survival of patients with late relapse is better, if they undergo complete surgical resection $[1,6,10,12,13]$.

Both seminomatous and nonseminomatous germ cell tumours can relapse after 2 years. Late relapse with nonseminomatous germ cell tumour patients is more frequent

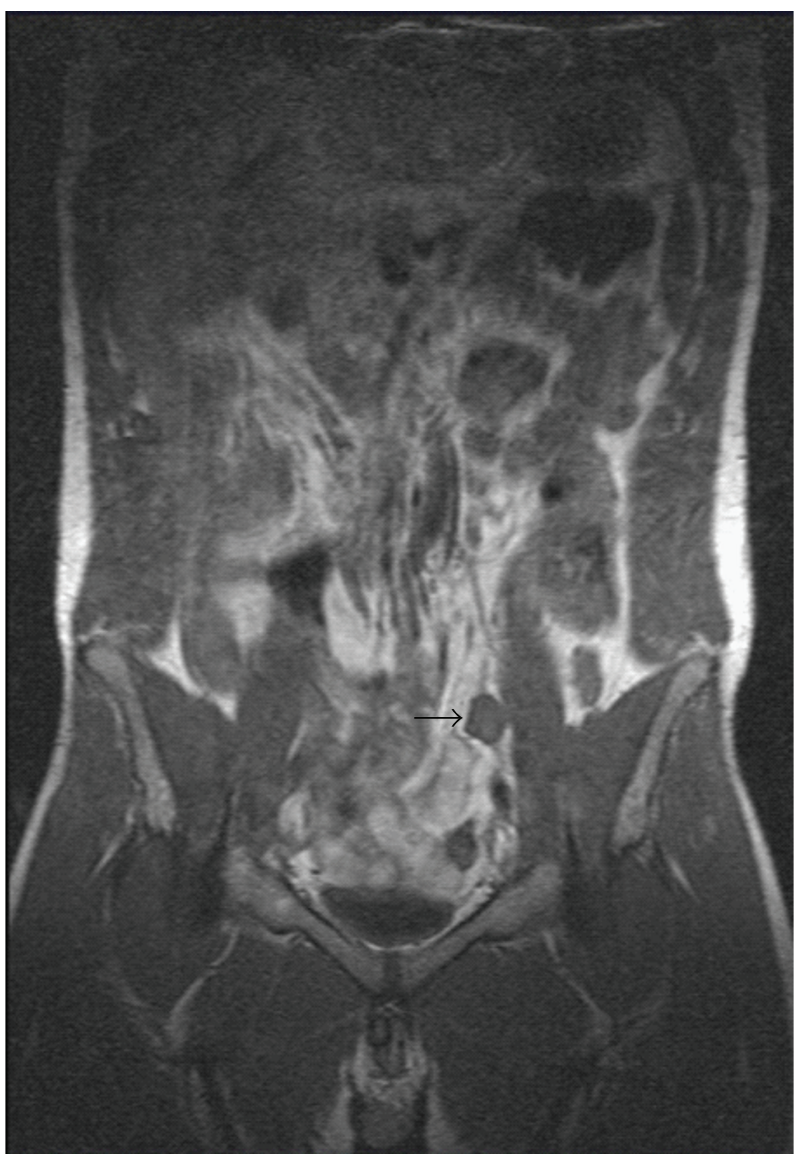

FIGURE 2: Coronal magnetic resonance imaging scan demonstrating $22 \mathrm{~mm}$ retroperitoneal lymph node (arrow).

$[7,10]$. Teratoma is the most common type of neoplasm in late recurrences, followed by yolk sac tumour. Other types of testicular tumours, including embryonal carcinoma, seminoma, choriocarcinoma, and nongerm cell malignant tumours occur rarely [14].

After the introduction of cisplatin-based chemotherapy for the treatment of testicular germ cell tumours, the survival of patients increase dramatically. Recently, the cure rate is excellent, even in the advanced stage. Testicular germ cell cancer occurs predominantly in young adulthood; therefore, these patients may experience high levels of risk as they reach older ages [15]. It resulted in increased focus on the serious treatment-related long term side effects, which can cause higher mortality rates. Many years after successful treatment, second primary malignancies can occur as the most serious late treatment side effect. Testicular cancer survivors are in greater risk of developing secondary tumours compared to the general population [2-4]. An increased incidence has been found following both radiotherapy and chemotherapy [2].

\section{Conclusion}

We can conclude that late followup of patients with testicular cancer is important. Patients treated for testicular cancer 
may need annual follow-up evaluations throughout their life because of the possibility of late relapse and second primary malignances as well. Retroperitoneoscopy is feasible approach for the removal of retroperitoneal lymph node metastasis and renal tumor resection even after open transperitoneal lymph node dissection.

\section{References}

[1] D. W. George, R. S. Foster, R. A. Hromas et al., "Update on late relapse of germ cell tumor: a clinical and molecular analysis," Journal of Clinical Oncology, vol. 21, no. 1, pp. 113-122, 2003.

[2] L. B. Travis, S. D. Fosså, S. J. Schonfeld et al., "Second cancers among 40,576 testicular cancer patients: focus on long-term survivors," Journal of the National Cancer Institute, vol. 97, no. 18, pp. 1354-1365, 2005.

[3] S. D. Fosså, J. Oldenburg, and A. A. Dahl, "Short- and longterm morbidity after treatment for testicular cancer," BJU International, vol. 104, no. 9 B, pp. 1418-1422, 2009.

[4] K. Pliarchopoulou and D. Pectasides, "Late complications of chemotherapy in testicular cancer," Cancer Treatment Reviews, vol. 36, no. 3, pp. 262-267, 2010.

[5] N. Borge, S. D. Fossa, S. Ous, A. E. Stenwig, and H. H. Lien, "Late recurrence of testicular cancer," Journal of Clinical Oncology, vol. 6, no. 8, pp. 1248-1253, 1988.

[6] J. Baniel, R. S. Foster, R. Gonin, J. E. Messemer, J. P. Donohue, and L. H. Einhorn, "Late relapse of testicular cancer," Journal of Clinical Oncology, vol. 13, no. 5, pp. 1170-1176, 1995.

[7] M. Shahidi, A. R. Norman, D. P. Dearnaley, J. Nicholls, A. Horwich, and R. A. Huddart, "Late recurrence in 1263 men with testicular germ cell tumors: multivariate analysis of risk factors and implications for management," Cancer, vol. 95, no. 3, pp. 520-530, 2002.

[8] J. Oldenburg, J. M. Martin, and S. D. Fosså, "Late relapses of germ cell malignancies: incidence, management, and prognosis," Journal of Clinical Oncology, vol. 24, no. 35, pp. 5503-5511, 2006.

[9] M. Pavic, P. Meeus, I. Treilleux, and J. P. Droz, "Malignant teratoma 32 years after treatment of germ cell tumor confined to testis," Urology, vol. 67, no. 4, pp. 846.e11-846.e13, 2006.

[10] M. E. Lipphardt and P. Albers, "Late relapse of testicular cancer," World Journal of Urology, vol. 22, no. 1, pp. 47-54, 2004.

[11] D. G. McLeod, R. B. Weiss, D. M. Stablein et al., "Staging relationships and outcome in early stage testicular cancer: a report from the testicular cancer intergroup study," Journal of Urology, vol. 145, no. 6, pp. 1178-1183, 1991.

[12] J. Oldenburg and S. D. Fosså, "Late relapse of nonseminomatous germ cell tumours," BJU International, vol. 104, no. 9 B, pp. 1413-1417, 2009.

[13] K. P. Dieckmann, P. Albers, J. Classen et al., "Late relapse of testicular germ cell neoplasms: a descriptive analysis of 122 cases," Journal of Urology, vol. 173, no. 3, pp. 824-829, 2005.

[14] H. Michael, J. Lucia, R. S. Foster, and T. M. Ulbright, "The pathology of late recurrence of testicular germ cell tumors," American Journal of Surgical Pathology, vol. 24, no. 2, pp. 257273, 2000.

[15] M. P. Coleman, G. Gatta, A. Verdecchia et al., "EUROCARE3 summary: cancer survival in Europe at the end of the 20th century," Annals of Oncology, vol. 14, no. 5, pp. v128-v149, 2003. 


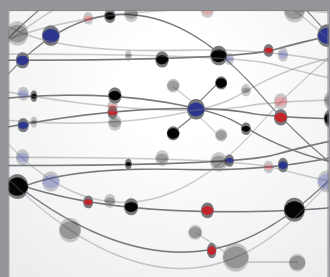

The Scientific World Journal
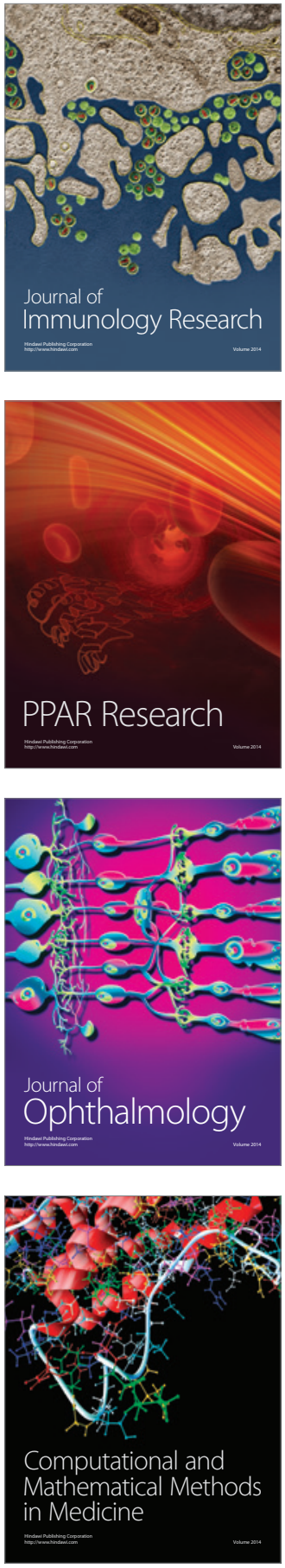

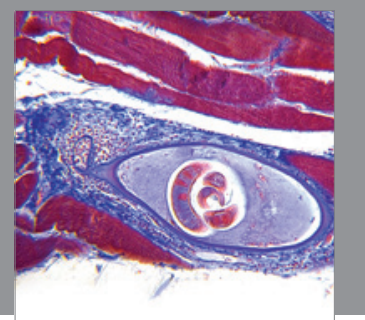

Gastroenterology

Research and Practice
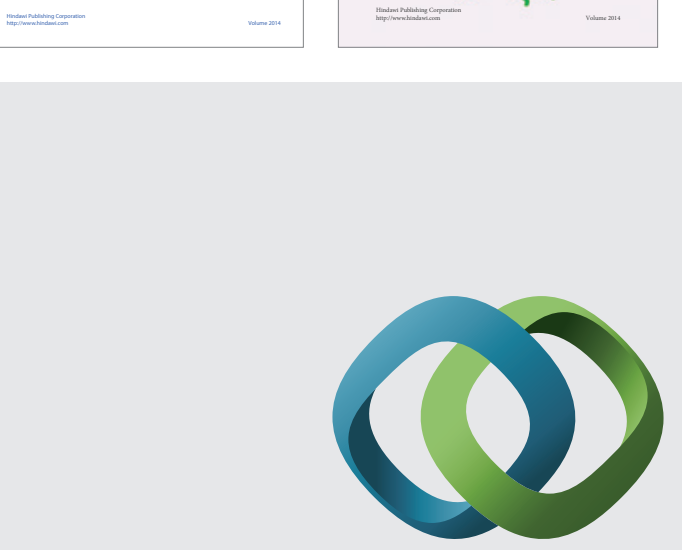

\section{Hindawi}

Submit your manuscripts at

http://www.hindawi.com
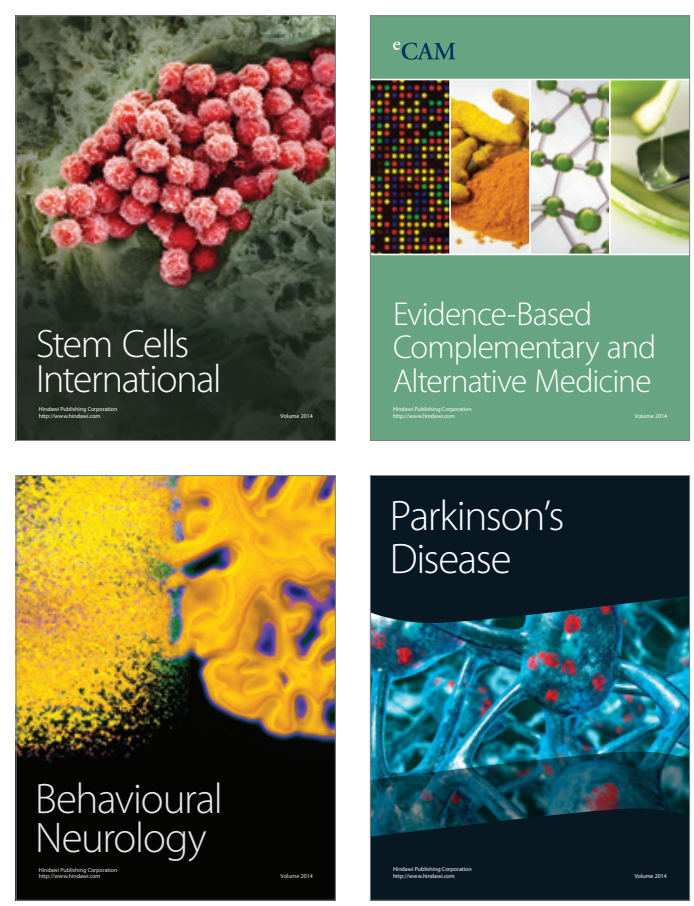

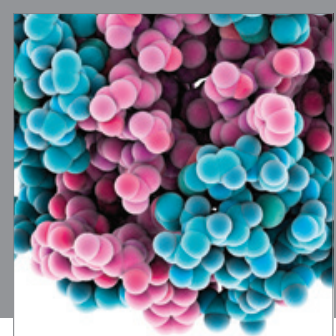

Journal of
Diabetes Research

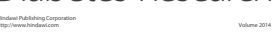

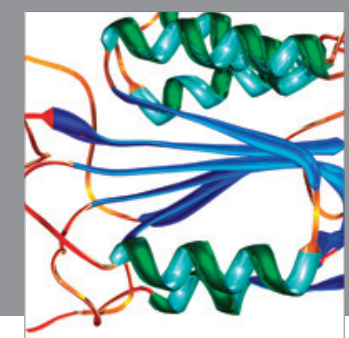

Disease Markers
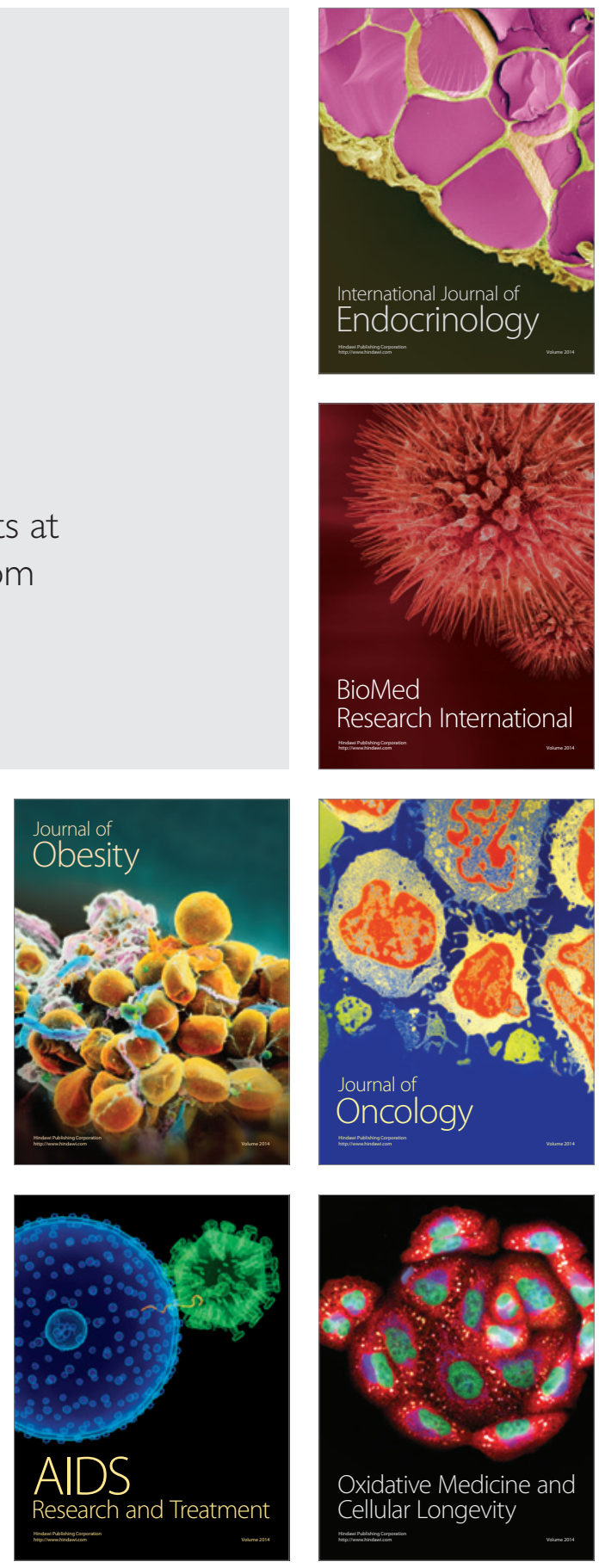